\title{
ONDE OS LAÇOS SE ATAM: SOCIABILIDADE E POLÍTICA NOS RELATÓRIOS DAS VIAGENS PEDAGÓGICAS DO INTELECTUAL NORTE-RIO- GRANDENSE NESTOR DOS SANTOS LIMA (1913-1923)
}

\author{
Sara Raphaela Machado de Amorim ${ }^{1}$ \\ lattes.cnpq.br/4398674052996842
}

\begin{abstract}
Resumo: Comissionado oficialmente como representante do Rio Grande do Norte, em 1923, Nestor dos Santos Lima lançou-se a conhecer o ensino nos centros de maior desenvolvimento educacional do Brasil, Argentina e Uruguai. Os saberes adquiridos foram organizados no seu relatório, onde expressa as relações estabelecidas, suas impressões e recomendações para a educação norte-rio-grandense. Enquanto escolhido para esta missão, se legitima no meio intelectual, ao passo que amplia suas redes, relações políticas e conhecimentos, obtendo o passaporte para a ocupação de novos cargos e espaços na educação do seu estado de origem. Para esta investigação, utilizo como fonte principal o relatório de viagem "Da Organização do Ensino Normal, Profissional e Primário no sul do Brasil e no Rio da Prata" (1923) em diálogo com outros documentos do período, como o jornal A República (1923) e a revista Pedagogium (1921; 1927), localizados no acervo do Instituto Histórico e Geográfico do Rio Grande do Norte (IHGRN). Na escrita dos relatórios, Nestor Lima apresenta autoridades que conheceu ou reencontrou. Assim, investigo como ele estrutura e amplia suas redes de sociabilidade e que repercussões estas redes tiveram em sua trajetória profissional.
\end{abstract}

Palavras-chave: Nestor Lima; Viagem; Educação; Sociabilidade; Política.

\section{WHERE THE BONDS ARE TIED: SOCIABILITY AND POLITICS IN THE REPORTS OF THE PEDAGOGICAL TRIPS OF THE NORTE-RIO- GRANDESE INTELLECTUAL NESTOR DOS SANTOS LIMA (1913-1923)}

Abstract: Officially commissioned as a representative of Rio Grande do Norte, in 1923, Nestor dos Santos Lima set out to know the teaching in the centers of greatest educational development in Brazil, Argentina and Uruguay. The knowledge acquired was organized in his report, in which he expressed the relations established, his impressions and recommendations for the norte-rio-grandense education. While chosen for this mission, he legitimizes himself in the intellectual environment whereas he

\footnotetext{
${ }^{1}$ Doutora em Educação. Docente da Universidade do Estado do Rio Grande do Norte (Brasil). Contato: raphaela.amorim@hotmail.com.
} 
expands his networks, political relations and knowledge, obtaining the passport to occupy new roles and spaces in the education of his home state. For this research, I use as main source the travel report of the "Organização do Ensino Normal, Profissional e Primário no sul do Brasil e no Rio da Prata" (1923) in dialogue with other documents of the period, such as the newspaper A República (1923) and the magazine Pedagogium (1921; 1927), located in the collection of Instituto Histórico e Geográfico do Rio Grande do Norte (HGRN). In the writing of reports, Nestor Lima presents authorities that he has met or rediscovered, therefore I investigate how he structures and broadens his networks of sociability and what repercussions these networks had in his professional trajectory.

Keywords: Nestor Lima; Trip; Education; Sociability; Politics.

\section{Considerações iniciais: percorrendo espaços de sociabilidade}

De acordo com Julliard (1984), as ideias não passeiam nuas pelas ruas; elas são levadas por homens que pertencem a conjuntos sociais. Com o objetivo de investigar as redes de sociabilidade e as relações entre intelectuais nos relatórios de viagens de Nestor dos Santos Lima, utilizo como base para esta análise os escritos que derivaram de suas missões comissionadas, realizadas nos anos de 1913 e 1923.

Nestor dos Santos Lima nasceu em Assu, município do interior do Rio Grande do Norte, em $1 .^{\circ}$ de agosto de 1887. Iniciou seus estudos primários com a sua mãe, Ana Souto Lima, matriculando-se, posteriormente, em instituições como o Atheneu Rio-Grandense e o Liceu Paraibano, onde concluiu o curso secundário em 1904. Em 1905, ingressou na Faculdade de Direito do Recife, pela qual recebeu o título de Bacharel em Ciências Jurídicas e Sociais em 16 de março de 1909.

Esteve à frente da direção da Escola Normal de Natal durante o período de 1911 a 1923. Responsável pela escrita dos relatórios de funcionamento da instituição, em 1912, o intelectual se utilizou deste espaço para que pudesse sugerir ao governador uma viagem com o objetivo de observar as práticas e o funcionamento de instituições educacionais nos estados considerados como referências neste particular. Assim, no ano 
seguinte, foi convidado para representar o Rio Grande do Norte nesta missão educacional. Estava de férias na capital da República, em 1913, quando recebeu um telegrama do então governador, Alberto Maranhão, que o comissionou a visitar as instituições, a fim de observar os melhoramentos técnicos do ensino primário e normal nos estados do Rio de Janeiro e São Paulo.

Dez anos após a realização da primeira viagem, em 1923, Nestor Lima lança-se novamente em missão comissionada, dirigindo-se à observação da estrutura e funcionamento da educação em outras localidades, desta vez avançando não somente para outros estados brasileiros, mas conhecendo também a educação em países como Argentina e Uruguai.

O impresso que se configura como meu cartão de embarque para este deslocamento é o relatório de viagem "Da organização do ensino normal, profissional e primário no sul do Brasil e no Rio da Prata" (1923). Para analisar este relatório faço menção ao escrito que resultou da primeira viagem, em 1913, sob o título "Melhoramentos técnicos do Ensino Primário e Normal" (1913). Observo a estrutura e organização dos dois relatórios escritos pelo educador, percebo que a primeira experiência lhe ofereceu subsídios para que, anos mais tarde, percorresse novamente por entre mares e estradas, porém com maiores ambições, desde o itinerário à ampliação dos contatos e redes.

Ao investigar os elementos que compõem os relatórios de viagens, me permiti fazer novos trajetos. Um deslocamento distinto, não mais a bordo dos navios e trens que levaram Nestor Lima (1923, p. 5) aos espaços visitados, mas a partir de escrita deste intelectual; novos caminhos que se constituem por meio do entendimento das relações, espaços e sujeitos, pois como ele mesmo escreveu:

Uma das primeiras e mais salutares consequências da minha viagem considero a oportunidade que se me deparou de realizar e estreitar relações amistosas entre aqueles grandes centros de cultura pedagógica e o nosso modesto meio escolar.

Nas primeiras páginas do relatório, o autor expressou sua compreensão para além da função oficial comissionada, destacando a importância dos contatos estabelecidos. A partir dessa exposição me questionei 
sobre quem eram essas pessoas, buscando compreender a viagem por outra dimensão, através dos relacionamentos constituídos a partir das redes de sociabilidade e relações políticas. Como identificar estas relações? Seriam elas determinantes para o percurso do viajante? Os contatos eram necessários à abertura de portas e autorização para as visitas que desejara realizar? Percorro os nomes e espaços que foram registrados durante os meses de travessia, como autoridades políticas e educacionais, numa hierarquia que se desenha no impresso e aponta algumas direções. Nomes que estão em evidência não somente no relatório de viagem, mas nos jornais e revistas do período investigado.

Nestor Lima, assim como muitos outros intelectuais, através do trânsito em diferentes instituições e da realização de viagens buscava estabelecer-se e legitimar-se, um movimento resulta na revelação de suas redes de sociabilidade. Nesse sentido, conforme afirma Bourdieu (1983, p. 127), "o reconhecimento, marcado e garantido socialmente por todo um conjunto de sinais específicos de consagração que os pares/concorrentes concedem a cada um de seus membros, é função do valor distinto de seus produtos [...]”. Assim, as aproximações dos sujeitos, as questões educacionais expressas em seus relatórios, como também suas motivações para a realização das viagens, são aspectos aqui analisados a fim de compreender o contexto educacional ora estudado, bem como as contribuições educacionais destes intelectuais em decorrência de tais redes de sociabilidade assim compostas.

Compreendo os esforços da viagem empreendida por ele, enquanto uma ação reveladora da motivação em ampliar e fortalecer contatos e alianças, o que ajuda a dimensionar suas redes de sociabilidade, apoio e prestígio, num movimento de busca por afirmação em meio aos diferentes grupos, contribuindo para o entendimento das categorias de análise intelectuais e sociabilidades a partir de seus microclimas, tensões e clivagens internas (SIRINELLI, 1996), evidenciadas "num jogo de omissões, sanções e exaltações possibilitadas através da escrita” (SIMMEL, 1997, p. 168).

Nos seus escritos, os espaços de sociabilidade apresentados dialogam com a sua formação e trajetória intelectual, desde sua formação na 
Faculdade de Direito do Recife (1909), as direções da Escola Normal de Natal (1911-1923) e do Departamento de Educação do Rio Grande do Norte (1924-1928), bem como os cargos assumidos no Instituto Histórico e Geográfico do Rio Grande do Norte (IHGRN). Admitido como sócio efetivo em fevereiro de 1910, foi orador, secretário da Revista do Instituto Histórico e Geográfico do Rio Grande do Norte em várias administrações e ao final eleito presidente em 17 de março de 1927, cargo que exerceu por 32 anos.

Nestor Lima transitava em diferentes instituições e espaços, conhecendo pessoas fortalecendo laços, redes e alianças. É, portanto, a partir de sua escrita que percebo o destaque que era dado a cada sujeito citado no relatório, devidamente localizado em seu ambiente de trabalho e, algumas vezes, com informações a partir de sua relação pessoal ou profissional com o indivíduo mencionado. Ele destaca, por exemplo, que em Buenos Aires fez as visitas acompanhado do Inspetor do Ensino Primário, Eloy Fernandez Alonso, "[..] que convidado para acompanhar-me nas visitas às escolas primárias, normais e profissionais, tornou-se um cicerone gentil e atencioso por todo o tempo dessas visitas" (LIMA, 1923, p.35).

O diálogo entre as fontes me apresenta um contato de difícil dissociação entre as relações sociais e políticas que subsidiaram os contatos e caminhos trilhados por Nestor Lima, pois:

[...] as trajetórias pedem naturalmente esclarecimento e balizamento, mas também e sobretudo interpretação. O estudo dos itinerários só pode ser um instrumento de investigação histórica se pagar esse preço. Sob a condição, entretanto, de evitar as generalizações apressadas e as aproximações duvidosas. (SIRINELLI, 2003, p. 244-247).

Para compreender a viagem em sua complexidade, escolhas e sentidos, é necessário olhar por "fora do navio". Questiono-me sobre quais relações e espaços constituíram o universo do viajante. A fim de perseguir estas informações, percorri os caminhos por onde Nestor Lima esteve em alguns momentos da sua vida. Busquei nos acervos do IHGRN, da Associação Brasileira de Educação (ABE), do Instituto Histórico e Geo- 
gráfico Brasileiro (IHGB), do Arquivo Público do Estado (APE) e da Academia Norte-Rio-Grandense de Letras (ANRL) os escritos que construíram o caminho pelo qual segui.

Nestes espaços de sociabilidade, observei atividades científicas e literárias, por entre as páginas dos jornais, revistas, relatórios, mensagens dos governadores, como o jornal A República (1923), a Revista Pedagogium (1921; 1927), a Revista A Educação do Grêmio Normalista (1921), a Revista do Instituto Histórico e Geográfico do Rio Grande do Norte (1922), a Revista do Instituto Histórico e Geográfico Brasileiro (1955) e a Revista Educação (1922). Seja a partir das divulgações dos eventos educacionais, políticos ou reuniões de intelectuais, entendo que as páginas destes periódicos davam destaques a alguns nomes e grupos e a notoriedade legitimada pelo trabalho desenvolvido na sociedade os colocava em uma posição de destaque e reconhecimento social.

Na travessia, por meio das motivações, descobertas e/ou (des)encontros, busco perceber, como alerta Ianni (2000, p. 28), que os caminhos do mundo não estão traçados,

ainda que haja muitos desenhados nas cartografias, emaranhados nos atlas, todo viajante busca abrir caminho novo, desvendar o desconhecido, alcançar a surpresa ou o deslumbramento. A rigor, cada viajante abre seu caminho, não só quando desbrava o desconhecido, mas inclusive quando redesenha o conhecido.

O poeta Antonio Machado (2003, p. 17) assegura: caminante, no hay camino, se hace camino al andar. Assim, convida-nos a pensar que o caminho não se faz sozinho. Os interesses em comum reuniram, durante séculos, sujeitos em busca de novos destinos. Busco, assim, elucidar que outras figuras acompanharam Nestor Lima na busca por novas direções para a educação no Rio Grande do Norte, antes, durante e depois do percurso comissionado. 


\section{A influência das relações políticas na tessitura das ideias, redes e alianças}

Uma viagem com fins educacionais e um governador que incumbiu Nestor Lima para tal missão; sujeitos localizados numa rede de relações, em busca do conhecimento dos modelos educacionais adiantados, a fim de garantir a qualidade do ensino que se buscava efetivar no Rio Grande do Norte da década de 1920. Pensando nestes aspectos e em suas interligações, como então entender a história da educação norte-rio-grandense sem relacionar seus processos de organização e transformação a partir das leis e dos documentos produzido se submetidos ao crivo da figura política do governador? A construção de uma nação por meio da educação e o combate ao analfabetismo figuravam como parte dos projetos políticos propostos no período. Considero importante entender as "engrenagens" complexas do meio intelectual que, conforme Sirinelli (2003, p. 248), nos mostram que:

Todo grupo de intelectuais organiza-se também em torno de uma sensibilidade ideológica ou cultural comum e de afinidades mais difusas, mas igualmente determinantes, que fundam uma vontade e um gosto de conviver. São estruturas de sociabilidade difíceis de apreender, mas que o historiador não pode ignorar ou subestimar.

Quando discute as estruturas elementares da sociabilidade, o autor afirma que o meio intelectual constitui, ao menos para seu núcleo central, um "pequeno mundo estreito", onde os laços se atam, por exemplo, em torno da redação de uma revista ou de um conselho editorial. Ele destaca que a linguagem comum homologou o termo redes para definir tais estruturas, possuidoras de inúmeras características e mais complexas do que se pode imaginar.

Ao investigar os processos de sociabilidade identificados em Nestor Lima, entendo as ações deste intelectual como indissociáveis das interfaces que a permeavam: os aspectos políticos. "[...] Pois esta história dos intelectuais remetia obrigatoriamente, por algumas de suas facetas à his- 
tória política [...]” (SIRINELLI, 2003 p. 234). Neste ponto, a escrita constitui uma prática de estabelecer e manter uma relação de redes políticas, sociais e intelectuais; a sociabilidade expressa nos impressos e que se dá no interior das estratégias de relacionamento pessoal e profissional. Os espaços por ele frequentados estão representados não somente nas publicações de seu próprio punho, como também no relato de outro viajante que passou por seu caminho. O professor Rocha Pombo, em sua visita a Natal no ano de 1917, por intermédio de seu conhecimento com o desembargador Ferreira Chaves, apresentou o que viu no amplo gabinete, a presença de muitas pessoas:

Naturalmente políticos, habitues do café oficial [...] estavam presentes Nestor Lima, Secretário do Instituto Histórico, advogado e professor; Ferreira Chaves, desembargador; Pedro Soares, coronel, vice-presidente do Instituto Histórico; Vicente Lemos, descrito como "desembargador, incansável investigador da história natalense"; Jeronymo Gueiros, Lente da Escola Normal; Isabel Gondim, poeta e educadora; Oscar Brandão, destacado como "Ilustre homem de letras"; Ferreira Chaves, desembargador; Santiago Varela, Diretor do Isolamento da Piedade, hospital para alienados." (SILVA, 2012, p.106)

Destacar o ambiente onde acontecem as ações dos indivíduos permite explicar a relevância das posições dos atores nos mais diferentes contextos de sociabilidade, resultante da complexidade e diversidade encontrada. Os processos sociais se estruturam nas práticas cotidianas, compondo elementos importantes dos perfis dos atores, assim como suas possibilidades de inserção nos distintos repertórios de ações. Para compreender a viagem em sua totalidade, busco destrinchar as relações entre as ideologias produzidas ou veiculadas por Nestor Lima e a cultura política de sua época. Entendo que na fronteira entre a história do intelectual e a história das ideias políticas encontro o contexto educacional que ora se formava. A relação estreita entre as ações políticas e educacionais no início do período republicano configura, no Rio Grande do Norte, o terreno fértil sobre o qual se desenvolve o pensamento de Nestor Lima, visto que as ações de cunho educacional foram passíveis de efetivação a partir de reformas e intervenções governamentais. 
Relembro ao leitor o conjunto de peças diferentes que compõe o acervo de fontes aqui utilizado. Desejo que acompanhe a tessitura dos laços e relações aqui apresentados, como este mosaico se constituiu e como o entrecruzamento de fontes nos aproxima de uma realidade vivida, ou ao menos representada. Dentre os autores que me inspiram na escrita dessa história, destaco o texto de Mignot (2002, p. 21) quando descreve com precisão e sensibilidade o sentimento de pesquisar a vida de Armanda Alvaro Alberto nas tramas do arquivo:

Considerar a vida não é tarefa de fácil concretização. O sonho de todo pesquisador revelou-se um quebra "cabeças". Paralisou. Imobilizou. Instigou. Fustigou. Armanda encontrava-se estilhaçada, fraturada, partida na variedade de documentos. Eles insinuavam, por vezes, várias interpretações. Grifados, sublinhados, destacados, comentados, obrigavam a descrever e rearticular. Apreensões efêmeras e apropriações violentas se revezavam. A trama do arquivo ficava ainda mais enredada no emaranhado de fios de uma rede de sociabilidade, tecida em diferentes espaços, com "ideias e afetos".

O trabalho com a história dos intelectuais, pode muitas vezes fazer com que o pesquisador se sinta ameaçado pelo que podemos chamar de "síndrome do mineiro", que diante da abundância de material a ser analisado e discutido, sente-se, como citado por Tocqueville. Lembrado por Sirinelli (2003, p. 244-245): "eu era como o minerador de ouro sobre cuja cabeça a mina tivesse desabado: estava esmagado sob o peso de minhas notas e não sabia mais como sair dali com o meu tesouro". Para driblar esta síndrome, permiti que a subjetividade emergisse como um importante elemento para a escrita. Através das leituras dos periódicos e documentos do período estudado, busquei me aproximar dos ambientes em que esteve Nestor Lima ao longo de sua vida. Como afirma Bourdieu (1987, p. 115), "leer, por tanto, no es un proceso automático consistente en captar un texto como un papel fotosensible fija la luz, sino un proceso de reconstrucción desconcertante, laberíntico, común a todos los lectores y al mismo tiempo personal".

A partir da história do pensamento de um sujeito, em diálogo com seus pares e em determinados espaços, escrevo acerca das categorias, 
projetos partilhados e incorporados na educação do Rio Grande do Norte. Através do intercâmbio da ideia de lugar, redes de sociabilidade e itinerário intelectual, torna-se possível vislumbrar o espaço social por onde o sujeito circulava, produzia e expressava suas ideias. Nesta teia, tecida pelas relações pessoais e profissionais, o meio é uma das condições para a elaboração intelectual.

No relatório, entendo os 89 sujeitos a partir de suas inserções na estrutura de redes sociais. O retrato destas redes indica a posição dos atores nos cenários, o que resulta no conhecimento das trajetórias biográficas que decorrem e são representadas pela posição que os sujeitos ocuparam na estrutura social, e como isto influência de algum modo na possibilidade das experiências vividas. O que significa dizer que é possível encontrar determinantes na estrutura social, a partir das ações e deslocamentos dos indivíduos. Neste sentido, o estudo das redes une as perspectivas micro e macro, porque permite o foco tanto na ação individual quanto no comportamento em um contexto estrutural mais amplo.

Nas rotas percorridas por Nestor Lima, alguns reencontros aconteceram. No Rio de Janeiro, reencontrou Antônio Carneiro Leão, antigo condiscípulo da Faculdade de Direito de Recife, foi diretor geral da Instrução Pública no Rio de Janeiro (1922 a 1926) e autor da Reforma da Educação no Estado de Pernambuco em 1928; atuou também como Secretário de Estado do Interior, Justiça e Educação do Estado de Pernambuco (1929-1930); diretor do Instituto de Pesquisas Educacionais da Prefeitura do Distrito Federal na administração Anísio Teixeira (1934); criador e diretor do Centro Brasileiro de Pesquisas Pedagógicas da Universidade do Brasil, dentre tantas outras atribuições.

Um conterrâneo de Nestor Lima, Amphilóquio Carlos Soares da Câmara está entre os sujeitos encontrados no Rio de Janeiro. Era o representante da delegação norte-rio-grandense na Exposição Internacional do Centenário. Este educador cursou humanidades no Atheneu Norte-rio-grandense, fez o pedagógico na Escola Normal de Natal e bacharelou-se em Ciências Jurídicas na Faculdade de Direito do Recife (1921).

Um fato que me chamou atenção nas aulas observadas e descritas por Nestor Lima é que apenas a uma ele retorna para segunda observa- 
ção. Era a sala de aula do professor Antônio Sampaio Dória, educador que teve seu nome diretamente ligado à reforma do sistema escolar paulista. De acordo com Carvalho (2010), em 1920 foi implantada, no estado de São Paulo, a Reforma Sampaio Dória, como ficou conhecida. Inverteu a lógica que vinha orientando a institucionalização e a expansão da escola no estado ao propor um programa fundamentalmente comprometido com as metas de erradicação do analfabetismo, e a difusão de um modelo escolar de educação básica capaz de promover a formação do cidadão republicano.

Qual a importância dos relacionamentos interpessoais para a realização de uma atividade profissional? Pensar no status conferido ao viajante e a espécie de certificação cultural que lhe é dada, é também discutir a teia de sustento que se forma por trás deste envio. Uma esfera composta por educadores e políticos que se articulam em busca da realização de um projeto, o desenvolvimento da educação popular:

Ninguém se forma no vazio. Formar-se supõe troca, experiência, interações sociais, aprendizagens, um sem fim de relações. Ter acesso ao modo como uma pessoa se forma é ter em conta a singularidade de sua trajetória e sobretudo o modo singular como age, reage e interage com seus contextos. Um percurso de vida é assim um percurso de formação, no sentido em que é um processo de formação. (NÓVOA apud MIGNOT, 2002, p. 62).

Dentre as relações políticas, destaco a forte ligação com o inicialmente deputado e posteriormente governador do estado do Rio Grande do Norte, José Augusto Bezerra de Medeiros. Um misto de amizade e parceria profissional expresso nas páginas dos jornais, revistas e documentos oficiais produzidos no período:

Adepto da Escola Nova, José Augusto foi um dos integrantes e entusiastas do movimento pela renovação da educação, ao lado de A. Carneiro Leão, Victor Viana, Mario Pinto Serva, Afrânio Peixoto, e, mais tarde, Heitor Lira, Sampaio Dória, Lourenço Filho, Edgard Süssekind, entre outros. Tal movimento foi ao que nos parece, pelos seus objetivos, um dos principais móveis para a perspectiva de fundação da Associação Brasileira de Educação (ABE), assim como, pelo incentivo desta, das reformas estaduais de ensino que, no Rio Grande do Norte, tiveram repercus- 
sões pela forma empreendida durante o governo do próprio José Augusto (1924 a 1927). (ARAÚJO, 1995, p. 3).

Assim como Nestor Lima, José Augusto exerceu vários cargos e foi responsável pela publicação de veículos educacionais, a exemplo da publicação e direção da revista A Educação (1922 a 1924) e da Revista Brasileira de Educação (1929); além da sua participação na $\mathrm{ABE}$, assumindo a Presidência nos anos de 1943, 1957, 1960 e 1961.

Na edição de 1924 da revista $A$ Educação, período da direção de José Augusto, Nestor Lima aparece como parte dos colaboradores, junto a nomes de relevo no panorama nacional como Carneiro Leão, Bertha Lutz, Juvenal Lamartine e Heitor Lyra da Silva. Entender as trajetórias dos sujeitos que não se fazem do nada, como fruto de convivências em espaços sociais e fortemente marcada por influências outras, é fundamental nesta análise que desenvolvo tomando como referência os estudos de Marta Araújo (1995, p. 20):

O desejo do conhecimento da trajetória político-intelectual de José Augusto, nas circunstâncias histórico-cultural vivenciadas, numa determinada época e lugares diferentes, leva-nos a inscrever este trabalho no procedimento das representações instituintes - perspectiva de apreender o sujeito alvo de interesse, instituindo-se na popularidade da herança cultural recebida e transformada em experiências singulares e genéricas - como as representou no conjunto de relações que construiu e nos processos em que formulou suas obras [...].

As transições e ocupações dos sujeitos nos espaços públicos são amplamente noticiadas. As Palavras de despedida, escritas no Jornal $A$ República (1923) por Nestor Lima, ao retornar de seu segundo trânsito comissionado, marcam publicamente o momento em que o educador se despede do cargo de diretor da Escola Normal para ocupar o novo posto de Diretor Geral da Instrução Pública em 1924, na gestão do então governador José Augusto Bezerra de Medeiros. Com base nas experiências adquiridas na viagem e nos cargos ocupados, ele cria o Departamento de Educação do Estado, um órgão que reflete a nova organização proposta a partir da política administrativa de José Augusto e que os documentos 
produzidos, regimentos e relatórios institucionais, esboçam a proposta resultante dessa parceria.

Os trâmites que dizem respeito às relações internacionais, a exemplo da autorização requerida para sua visita no país estrangeiro, são citados como etapa da atividade profissional, seguidos de menções pessoais relacionadas às atitudes por parte dos responsáveis pelos processos burocráticos:

Conhecedor das necessidades que me levavam ali, o Consul Brasileiro comunicou-se logo com o dr. Enrique Loudet, um notável médico argentino e grande amigo do Brasil, pertencente ao Corpo Médico Escolar do Conselho Nacional de Educação, expondo-lhe o fim da minha visita. E, incontinente, transportando-me eu ao Conselho Nacional, fui lá recebido pelo dr. Loudet, que foi o liame dos meus interesses com o pessoal dirigente e docente do ensino buenairense. (LIMA, 1923, p. 35)

Em meio a estes trâmites, menciona as cartas enviadas cartas ao Ministro do Exterior, cônsul brasileiro Alberto Baez Conrado, assim como posteriormente ratifica o intermédio que José Augusto fez a fez a alguns dos seus amigos em São Paulo. "Nosso eminente representante, dr. José Augusto, me recomendara por telegrama a vários amigos seus, que ali são autoridades escolares" (LIMA, 1923, p. 55).

Nestor Lima representa a história que se constrói no itinerário. Essa construção se dá a partir do caminho percorrido, mencionando pessoa a pessoa que encontrou, detalhes dos comportamentos em relação à receptividade em determinadas instituições e como cada sujeito é ponte para novo contato:

Encontrei por parte das autoridades e dos profissionais do ensino na Argentina, no Uruguai, em São Paulo, em Belo Horizonte e no Rio, um intenso desejo de permutação de esforços, no sentido de conhecermo-nos reciprocamente acompanharmos com o interesse devido todas as realizações atinentes ao problema educativo e avaliarmos os resultados obtidos com as modificações do aparelho e da técnica pedagógica. (LIMA, 1923, p. 5)

As relações internacionais e interestaduais são destacadas no item "Intercâmbio pedagógico", onde escreve sobre questões sociais, como a 
relação infundada de ciúmes e orgulho entre Brasil e Argentina, destacando o papel da imprensa neste particular. Afirma que só por vaidade, orgulho e despeito, sentimentos de tão baixa cotação não devem inspirar as nações entre si. Alerta que pouco deve importar a voz apaixonada da imprensa mal orientada, que trabalhava a serviço dos negocistas e sua visão dos lucros nas compras de armamentos, preparando assim a ruína dos países amigos e irmãos. O discurso circunscreve-se na necessidade de haver um ensino que possibilite a ampliação das relações e a quebra da luta injusta e injustificada entre brasileiros e argentinos.

\section{Considerações finais}

Entendo que as relações e experiências de certo modo produzem o sujeito e o que dele deriva. Concordo com Chamon (2005) quando destaca que contar a história de uma vida, levando em conta a noção de experiência, significa pensar que os indivíduos se constituem por meio de experiências diversas, condicionadas pelo lugar social que ocupam. Isso nos leva a pensar que essas experiências são perpassadas pelas condições econômica, religiosa, étnica, de gênero, de geração, etc. Vivências que passam a ser entendidas como o que produz o sujeito e sua identidade.

$\mathrm{O}$ conhecimento das redes e relações políticas reporta aos valores das elites do Rio Grande do Norte dos anos iniciais do século XX. Entender quem são estes sujeitos que estão à frente da política e da educação norte-rio-grandense, seus movimentos e as influências educacionais me faz crer que, como afirma Ginzburg (1987), a rede interpretativa era de longe mais importante do que a fonte. Neste contexto, destacava-se a educação escolar, por ser a educação que preparava letrados e bacharéis para as carreiras no funcionalismo público.

Nestor Lima, viajante, se tornou tradutor/mediador entre duas realidades. As relações sociais e as viagens possuem um movimento intrínseco, que o fizeram capaz de ampliar seu conhecimento, aprimorar saberes e revelar novos referenciais. A viagem, por meio dos olhos e da escrita do viajante, o colocou em contato dois mundos. Tendo visto a constitui- 
ção das redes, percebo também sua ampliação a partir da visitação de novos espaços. Um trânsito se relaciona com outro. Os conhecimentos e relacionamentos adquiridos o levaram à frequentar novos círculos, como exemplo das viagens para o $8 .^{\circ}$ Congresso de Geografia, sediado em Vitória, Espírito Santo, em 1926, e para a Conferência Nacional da Educação, realizada em 1927, na cidade de Curitiba, (re)encontrando muitos dos intelectuais citados anteriormente em seus relatórios de viagens.

Assim como os espaços físicos e instituições aqui apresentadas constituíam pontos de encontro e sociabilidade, outro espaço, não mais constituído por estruturas arquitetônicas, possibilitava interações entre os intelectuais e de certo modo formava-se como ponto de encontro e/ou desencontro de ideias. Os jornais e revistas revelam-se não somente veículos de disseminação das ideias e movimentos dos intelectuais, como também palco de embates ideológicos.

O uso da narrativa aqui é feito, sabendo que ela é construída por um sujeito histórico e que sua formação, visão de mundo e objetivos podem influenciar de forma decisiva na tessitura de seus textos. Segundo Eco (2005), um texto é um universo indefinidamente aberto, no qual o interprete pode descobrir interligações infinitas, sendo a linguagem incapaz da apreensão de um sentido único e preexistente.

Entendo que, com base na intencionalidade da escrita, a relação de proximidade que o pesquisador estabelece com suas fontes, necessita em alguns momentos do movimento de distanciamento e estranhamento a partir das indagações sobre o que ali está construído. "O leitor é sempre pensado pelo autor, pelo comentador e pelo editor como devendo ficar sujeito a um sentido único, uma compreensão correta, a uma leitura autorizada" (CHARTIER, 1990, p. 123). Pensar em um relatório que possuía finalidades específicas, abre espaço para o questionamento de produção deste escrito para um público também específico, com ações bem delineadas, como nos alerta o autor para não ignorarmos os processos através dos quais um texto faz sentido para aqueles que leem.

É impossível olhar para os documentos produzidos no período do mesmo modo. Depois de conhecer mais sobre a vida de Nestor Lima, ver os laços atados no decorrer do percurso, assim como as relações sociais e 
políticas que estabeleceu, os diálogos com as fontes à luz das referências teóricas me conduziram a ver o que estava "por trás" de cada iniciativa. O que impossibilita perceber muitas das ações de organização do ensino no estado sem a influência das ideias, projetos políticos e educacionais que corroboraram para a criação de Grupos Escolares, Escolas Isoladas, Escolas Rudimentares e Departamento de Educação.

Historicamente, diversas iniciativas centralizaram os professores como foco de investimentos para as transformações sociais que se desejava fazer. A este exemplo, os manuais pedagógicos e de conduta, os relatórios de viagem publicados, as revistas educacionais, bem como os jornais que, possuíam espaço específico para a discussão das problemáticas educacionais, possibilitaram os encontros de profissionais de diversas áreas para a discussão sobre o futuro da nação por meio da educação. Nestes campos, teorias, práticas e pessoas construíram um leque de conhecimentos mundialmente partilhados. Estes sujeitos, em geral, donos de uma nova visão adquirida nos espaços por onde transitavam, nas experiências vividas e nos contatos que estabeleciam. Era preciso ampliar a visão. Eram necessários outros olhares.

\section{Referências}

AMORIM, S. R. M. Viagem como missão: intercâmbio pedagógico do educador Nestor dos Santos Lima (1913-1923). Tese (Doutorado em Educação), Universidade do Estado do Rio de Janeiro, Rio de Janeiro, 2017.

ANTONIO MACHADO, Provérbios y cantares. El País, clasicos del siglo XX, Madri, 2003, p 17.

ARAÚJO, M. M. José Augusto Bezerra de Medeiros: político e educador militante. 2. ed. Natal: EDUFRN; Assembleia Legislativa do Rio Grande do Norte; Fundação José Augusto. 1999.

DUBY, G. A História continua. Rio de Janeiro: Zahar, 1994.

CHAMON, C. S. A trajetória profissional de uma educadora: Maria Guilhermina e a pedagogia Norte-Americana. Tese (Tese de Doutorado). Universidade Federal de Minas Gerais, Belo Horizonte, 2005. 
IANNI, O. A metáfora da viagem. In: Enigmas da modernidade-mundo. Rio de Janeiro: Civilização Brasileira, 2000.

JULLIARD, J. Sur un fascisme imaginaire : à propos d'un livre de Zeev Sternhell. In: Annales. Économies, Sociétés, Civilisations. $39^{e}$ année, n. 4, p. 849-861, 1984.

LIMA, N. S. Da organização do ensino normal, profissional e primário no sul do Brasil e no Rio da Prata. Natal: Typ. d'A República, 1923.

. Melhoramentos técnicos do ensino primário e normal. Natal: Typ. do Instituto, 1913.

LOPES, E. M.; GALVÃO, A. M. Introdução. In: História da Educação. Rio de Janeiro: DP\&A, 2005.

MEDEIROS, J. A. B. (org.) A Educação. Rio de Janeiro: Imprensa Geográfica Editora, 1924.

MIGNOT, A. C. V. Baú de memórias, bastidores de histórias: o legado pioneiro de Armanda Álvaro Alberto. Bragança Paulista: EDUSF, 2002.

SILVA, A. L. Escritas de viagem, escritas da história: estratégias de legitimação de Rocha Pombo no campo intelectual. Tese (Doutorado em Educação), Universidade do Estado do Rio de Janeiro, Rio de Janeiro, 2012.

SIRINELLI, J.-F. Os intelectuais. In: REMOND, R. (org.). Por uma história política. Rio de Janeiro: Fundação Getúlio Vargas, 2003, p. 231269.

\section{Periódicos}

Revista A Educação - Órgão do Grêmio Normalista (1921).

Revista Pedagogium. Empresa Tipográfica Natalense LTD, Natal: 1921. Revista do Instituto Histórico e Geográfico Brasileiro (RIHGB), Rio de Janeiro: Departamento de Imprensa Nacional, 1944. 